\title{
Value-added Evaluation of College Students' English learning efficiency based on \\ Hierarchical linear model
}

\author{
Kong Su-ran \\ Basic Science Department \\ Beijing University of Agriculture \\ Beijing, China \\ Email:kongsr@126.com \\ Li Guang-li \\ Beijing Normal University Library \\ Beijing Normal University \\ Beijing, China \\ Email: ligl@bnu.edu.cn
}

\author{
Jiang Li-hui \\ Basic Science Department \\ Beijing University of Agriculture \\ Beijing, China \\ Email:lihuijiang_010@163.com \\ Wang Hui-chuan ${ }^{*}$ \\ Basic Science Department \\ Beijing University of Agriculture \\ Beijing, China \\ Email:whch56221@sohu.com \\ * Author for correspondence
}

\begin{abstract}
Value-added evaluation" is widely applied to school efficiency evaluation of primary and secondary school. But there are few applications of college students' evaluation. Firstly, null model of College students' English learning efficiency has been established based on Hierarchical linear model in order to find out which is more important factor between students' and teachers' factor. Secondly, only level-1 predicators' model of College students' English learning efficiency has been established based on Hierarchical linear model in order to quantify the influence of every variable of students to outcome variable. Finally, "value-added evaluation" model of College students' English learning efficiency has been established based on Hierarchical linear model. An empirical research of an agricultural college was carried out to illustrate the necessity of value-added evaluating application to College students' English learning efficiency.
\end{abstract}

Keywords: Hierarchical Linear Model (HLM); College students' English learning efficiency; Value-added evaluation.

\section{INTRODUCTION}

Learning evaluation is an important component of higher education evaluation and plays an important role in promoting the education reform. In recent years there are many researches on College Students' English learning evaluation, but most of them focused on qualitative evaluation or consequential evaluation. Qualitative evaluation to College students' English learning mostly described current situation from the teachers' teaching experience. These evaluations are subjective evaluation lacking of quantitative evaluation standard, which is likely to be questioned by others; Consequential evaluation evaluated students from their scores from a certain examination, with their foundation neglected. Therefore, it is necessary to propose a new evaluation method named "value-added evaluation" to College students' English learning. The evaluation results will help to stimulate students' interest in learning and to improve students' learning enthusiasm.

"Value-added evaluation" was developed for the research of school efficiency in Britain and America ${ }^{[1]}$. So-called "value-added" is the increasing value of students for some time. It is an evaluation method from students' scores for several times, which excludes some factors that school and teacher cannot control "2]. "Value-added evaluation" emphasizes developing evaluation, not consequential evaluation ${ }^{[3]}$. The progress can be calculated from comparing students' final actual scores and predicted scores. More and more specialists and 
scholars have paid attention to "value-added evaluation". Most of them have focused on evaluation to primary and secondary school efficiency. Some others have focused on evaluation to the quality of teaching. However, there has been little research about application of College students' English learning efficiency until now.

Therefore, the value-added evaluation model of College students' English learning efficiency is necessary to be established basing on Hierarchical linear model. The factors influencing College students' English learning efficiency and the progress in English learning for College students will be found out by a case of an agricultural college. Some advice will also be given for teaching and learning.

\section{HIERARCHICAL LINEAR MODEL(HLM)}

"Value-added evaluation" which is widely developed benefited from the development of hierarchical linear model. HLM first qualifies the influence factors, and then designs multilevel regression equation, finally investigates each level variables effecting on outcome variable. Actually, the added value is the residual which is the difference of the outcome variable actual value and predicted value of hierarchical linear model.

The basic principle of hierarchical linear model divided the outcome variable level into two parts where one is the individual difference within group and the other is difference between groups. The model first overcame the shortcomings indicating residual by single form and ignoring internal relevance between individuals, then provided residuals in each level, and then took into cohort effects account. So it could present more accurate and positive result. There is two and three levels model in hierarchical linear model.

The research is about the evaluation of College students' English learning efficiency influenced by teachers and students. So the hierarchical linear model of two levels was adopted. The basic form is:

Level one model (individual):

$$
Y_{i j}=\beta_{0 j}+\beta_{1 j} X_{i j}+r_{i j}
$$

Level two model (group):

$$
\beta_{0 j}=\gamma_{00}+u_{0 j}
$$

$$
\beta_{1 j}=\gamma_{10}+u_{1 j}
$$

Substituted $\beta_{0 j}$ and $\beta_{1 j}$ in Equation (1):

$$
Y_{i j}=\gamma_{00}+\gamma_{10} X_{i j}+\left(u_{1 j} X_{i j}+r_{i j}+u_{0 j}\right)
$$

Where the $j$ subscript of $\beta$ coefficients indicates that vary over groups. The $r_{i j}$ term is the random effect or residual for the $i$ th individual in the $j$ th group, assumed to be independently and normally distributed with mean of 0 and constant variance of $\sigma^{2}{ }^{[5]} . Y_{i j}$ is the variable treated as the outcome variable; $\gamma_{00}$ and $\gamma_{10}$ which are the average of $\beta_{0 j}$ and $\beta_{1 j}$ are constant in level two and the fixed components of $\beta_{0 j}$ and $\beta_{1 j} ; u_{0 \mathrm{j}}$ and $u_{11}$ representing the variation between level two variables are random components of $\beta_{0 j}$ and $\beta_{1 j}$

\section{AN EMPIRICAL RESEARCH}

\section{A. Data collection and arrangement}

The object population in this paper is undergraduates admitted by an agricultural college in 2010 . We collected 975 copies of valid data accounting for $74 \%$ of the total number of students. Following the objective and available principles, we selected the following variables to evaluate English learning efficiency.

Variables in Level one: (a) ZCG: CET-4 scores, standardized as outcome variable; (b) GEN: gender variable, assign female to 0 and male to 1 ; (c) DOM: place of domicile, assign students from Beijing to 1 and students from other provinces to 0; (d) DCA: subjects studied in high school, assign science to 1, assign Liberal arts to 0; (e) ZEnS: English scores in the college entrance examination, standardized with the class as a unit;

Variables in Level two: (a) Tyear: years of teacher teaching in the agricultural college; (b) Tlevel: teachers' professional titles, assign associate professor to 1 , assign 
lecturer to 2, assign assistant to 3; (c) CPR: the ratio of passing CET-4 examination in each class; (d) CAS: the average scores of each class.

TABLE1. RANDOM EFFECTS ESTIMATION IN NULL MODEL

\begin{tabular}{cccccccc}
\hline \multicolumn{8}{c}{$u_{0}$} \\
\hline & $\mathrm{SD}$ & $\mathrm{VC}\left(\tau_{00}\right)$ & $\mathrm{SD}$ & $\mathrm{VC}\left(\sigma^{2}\right)$ & $\rho$ & $\chi^{2}$ & $p$ \\
\multirow{2}{*}{$\mathrm{ZCG}$} & 0.1850 & 0.0342 & 0.9857 & 0.9717 & 0.034 & 36.1212 & $<0.01$ \\
\hline
\end{tabular}

Then, the value-added evaluation model about above all variables will be established by SPSS 19.0 and HLM 7.0 .

\section{B. Value-added evaluation model about CET-4 scores}

\section{1) Null model}

Firstly, the prediction model only including outcome variable was established.

Level-1 model:

$$
\begin{gathered}
Y_{i j}(Z C G)=\beta_{0 j}+r_{i j} \\
\operatorname{Var}\left(r_{i j}\right)=\sigma^{2}
\end{gathered}
$$

Level-2 model:

$$
\begin{gathered}
\beta_{0 j}=\gamma_{00}+\mu_{0 j} \\
\operatorname{Var}\left(\mu_{0 j}\right)=\tau_{00}
\end{gathered}
$$

From Table 1, we knew that the level-1 variation is $\sigma^{2}$ equals to 0.972 and the level- 2 variation is $\tau_{00}$ equals to 0.034 . We calculated the intra-class correlation $\rho=\tau_{00} / \tau_{00}+\sigma^{2}=0.034$, which indicates that the 3.4 percent variation of total variation of CET-4 scores is induced by level-2 variables and the 96.6 percent variation of total variation of CET- 4 scores is induced by level-1variables. It shows that students themselves are the main factor in English learning, but teachers cannot be ignored. The variations from level-1 and level-2 are both significant (the value of $\chi^{2}$ and $p$ are both significant). It indicates that there is significant difference between students of different classes in CET-4 scores and variation which cannot be explained in two levels, so it is necessary to introduce the level-1 predictors.

\section{2) Model only including level-1 predictor}

Based on null model, the random slope model by introducing all level-1 variables was established in order to find out the influence of level-1 variables to CET-4 scores.

Level-1 model:

$$
\begin{aligned}
Z C G= & \beta_{0}+\beta_{1}(\mathrm{GEN})+\beta_{2}(D O M) \\
& +\beta_{3}(D C A)+\beta_{4}(\mathrm{ZEnS})+r
\end{aligned}
$$

Level-2 model:

$$
\beta_{j}=\gamma_{j 0}+\mu_{j}, j=0,1,2,3,4
$$

It indicates that GEN、DOMI、DCA and ZEnS all have significant influence to English learning, which is testified by statistical indicator ( $p$-value $<0.01$ ). From the coefficients we can conclude as follows: (1)there is highly positive correlation between CET-4 scores and English scores in the college entrance examination, meaning that English scores in the college entrance examination increased one unit and CET-4 scores will increase 0.704 unit; (2)there is positive correlation between CET-4 scores and the place of domicile, meaning that the scores of students who comes from Beijing are higher 0.395 unit than those who comes from other provinces; (3)there is negative correlation between gender and CET-4 scores, meaning that 0.032 CET-4 scores of the class will be increased if there is one more female in class; (4)there is negative correlation between subjects studied in high school and CET-4 scores, meaning that the scores of students who studied science subject are lower 0.169 unit than those who studied liberal art subject. So the foundation of students has significant influence to CET-4 scores and we should not evaluate students learning or teaching quality by rigid results. We should focus on the difference of students' 
and evaluate them by progress they made for some time.

Therefore it is necessary to introduce full model of

TABLE2. RANDOM EFFECTS ESTIMATION IN MODEL 2)

\begin{tabular}{cccccc}
\hline Level-1 variables & Parameters & coefficients & $\begin{array}{c}\text { Standard } \\
\text { Error }\end{array}$ & T-ratio & p-value \\
& $\gamma_{00}$ & -0.028 & 0.069 & -0.413 & 0.692 \\
GEN & $\gamma_{10}$ & -0.032 & 0.057 & -5.577 & $<0.01$ \\
DOM & $\gamma_{20}$ & 0.395 & 0.0767 & 5.170 & $<0.01$ \\
DCA & $\gamma_{30}$ & -0.169 & 0.06 & -2.843 & $<0.01$ \\
ZEnS & $\gamma_{40}$ & 0.704 & 0.029 & 24.510 & $<0.01$ \\
- & $\sigma^{2}$ & 0.558 & - & - & - \\
- & $\tau_{00}$ & 0.038 & - & - & - \\
- & $2 \times \log ($ like $)$ & 2230.69 & - & - & - \\
\hline
\end{tabular}

\section{3) Full model}

Based on model the model only including level-1 predictor, the random slope model by introducing level-2 variables was established in order to study the influence of level-2 variables to CET-4 scores and make clear the progress the students made in two years.

Level-1 model:

$$
\begin{aligned}
Z C G= & \beta_{0}+\beta_{1}(\mathrm{GEN})+\beta_{2}(\mathrm{DOM}) \\
& +\beta_{3}(\mathrm{DCA})+\beta_{4}(\mathrm{ZEn} S)+r
\end{aligned}
$$

Level-2 model:

$$
\begin{aligned}
& \beta_{j}=\gamma_{j 0}+\gamma_{j 1}(\text { Tyears })+\gamma_{j 2}(\text { Tlevel }) \\
& +\gamma_{j 3}(C P R)+\gamma_{j 4}(C A S)+\mu_{j}, j=0,1,2,3,4
\end{aligned}
$$

The fitting variance of three models is decreasing and all reached the significant level meaning that full model can perfectly explain the influence of students' and teachers' variables to CET-4 scores. We calculated the residual of full model as the added value of college students' English learning efficiency. Because of the limitation of length, no more tautology here. Only the average added value、 the average CET- 4 scores and pass rate by CET-4 were listed as follows (Table 3 ) :

Comparing the three sorted results, we can draw the conclusion that average sort and pass rate sort are similar and they both are different from value-added sort. The correlation coefficient between average sort and pass rate sort is 0.929 , showing that there is highly positive correlation between them. But the correlation coefficient between average sort and value-added sort is very low, showing that there is lack of correlation coefficient between them. Average sort and pass rate sort are evaluating methods from students' final scores reflecting their final achievement levels. If students are only judged by their final achievement levels and always have horizontal comparison to other students, they will never feel a sense of accomplishment if they cannot surpass others. It will hurt their self-esteem and learning initiative. Therefore it is very necessary to evaluate students by value-added evaluation in practice, judging them by learning process and progress.

There is lack of correlation coefficient between value-added sort and teachers teaching years and their professional titles, showing that value-added of students are also relevant to the objective indicators such as teaching years and professor title;

In conclusion, to learning English well students should know why to learn and how to learn. Learning English is not only for English course but also is for life. Teachers must fully arouse the enthusiasm and subjective initiative of students in order to improve the college students' English learning efficiency. The mobilization of enthusiasm and subjective initiative of students depends on teachers how to deal with the teaching content and how to design the teaching method, which makes students willing to learn and glad to learn. 
TABLE 3. LIST THE AVERAGE、VALUE-ADDED、AVERAGE、 PASS RATE AND THEIR SORTS

\begin{tabular}{ccccccc}
\hline $\begin{array}{c}\text { Teacher } \\
\text { code }\end{array}$ & $\begin{array}{c}\text { average } \\
\text { value-added }\end{array}$ & $\begin{array}{c}\text { Value-added } \\
\text { sort }\end{array}$ & average & average sort & pass rate & pass rate \\
sort
\end{tabular}

\section{CONCLUSION}

Taking above three models results and discussion into consideration, we naturally come to the following conclusions:

Firstly, the factors affecting college students' English learning efficiency includes students' and teachers' factors, where the ratio of students' and teachers' factors is 96.6 to 3.4. So students' factors are main factors affecting college students' English learning efficiency. Only totally understanding the factors influencing College Students' English learning efficiency, can teachers and students constantly adjust teaching method and learning method in order to improve the ability of English comprehensive application. Teachers can fully find out the difference of each student, truly "shoot the arrow at the target", and then teach students in accordance with their natural ability and finally help students to be able to use English freely.

Secondly, the variables of students' foundation have significant influence to English learning efficiency, where the most of them is English scores in the college entrance examination followed by place of domicile and subjects studied in high school and gender. Thus foundation is important in English learning. English learning is a long-term learning process. To practice English very well, students should encourage enthusiasm and keep trying consistently.

Finally, the value-added is not consistent with the results from the conclusion of full model. The value-added evaluation pays more attention to progress and achievement made by students. It can easily arouse the enthusiasm and initiative of students and is more beneficial for students to improve the ability of English comprehensive application. Maybe let English learning be a part of life.

\section{REFERENCES:}

[1] GUO Rui\& NIE Wei, "On the Research Status and Application of Education Value- added Evaluation,” J. Journal of Changchun Normal University (Humanities and Social Sciences), vol. 29, May. 2001, pp, 136-138.

[2] ZHOU Yan \& BIAN Yufang, "Value- Added Assessment of Teacher Effectiveness in American:Development in Research and Practice,” J. Global Education, vol. 40, Nov. 2011, pp, 72-78.

[3] BIAN Yu-fang, LIN Zhi-hong. "Value-Added Evaluation: A Developmental Evaluation Model for "Green Enrollment Ratio","J. Journal of Beijing Normal University(Social sciences), vol. 40, Jun. 2007, pp, 11-18

[4] Lei Chang. Applied Multilevel Data Analysis[M]. Beijing: Education Science Publishing House,2003.

[5] Richard Tate. "Interpreting Hierarchical Linear and Hierarchical Generalized Linear Models with Slopes as Outcomes,"J.The Journal of Experimental Education, vol. 73, Jan. 2004, pp, 71-95. 